\begin{tabular}{|c|c|c|}
\hline & Int.J.Curr.Microbiol.App.Sci (2021) 10(12): 22-27 & \\
\hline & $\begin{array}{l}\text { International Journal of Current Microbiology and Applied Sciences } \\
\text { ISSN: 2319-7706 Volume } 10 \text { Number } \mathbf{1 2} \mathbf{( 2 0 2 1 )} \\
\text { Journal homepage: } \underline{\text { http://www.ijcmas.com }}\end{array}$ & $\$ 0$ \\
\hline $\begin{array}{l}\text { EXCELLENT } \\
\text { PUBLISHERS }\end{array}$ & & \\
\hline
\end{tabular}

\title{
Comparison of Routine and Stool Concentration Techniques for Microscopic Detection of Intestinal Ova and Cysts in the Tertiary Care Hospital of Northern India
}

\author{
Sana Jamali, Sarver Jahan* and Megha Chaudhary
}

Department of Microbiology, Integral Institute of Medical Sciences and Research (IIMSR), Lucknow, India

*Corresponding author

\section{A B S T R A C T}

\section{Keywords}

Stool Concentration techniques, Ova, Cyst, Floatation, Sedimentation techniques

\section{Article Info}

Received:

05 November 2021 Accepted: 28 November 2021 Available Online: 10 December 2021
Human intestinal parasitic infestations have a worldwide distribution. In developing countries parasitic infestation is one of the serious health problem causing significant morbidity. The main objectives of this study to compare the routine and stool concentration techniques for parasitic ova and cysts detection so as to emphasize the importance of concentration techniques. A descriptive analysis of stool samples received from 118 study participants during a period of six months were carried out. Four techniques were applied on all samples which included direct microscopic examination by using saline and iodine preparations and the two concentration techniques which included simple salt floatation technique and Formal-ether concentration technique, followed by microscopic examinations. In routine technique $30.5 \%$ of patients were positive for ova/cysts. $33.9 \%$ of patients were positive for ova/cysts of parasites by saturated saline floatation technique. Highest positivity was found by formal ether sedimentation technique (39\%).The most common parasite which was detected was Entamoeba histolytica/dispar (16-20\%) followed by Blastocystis hominis (6-12\%). Concentration techniques (formal-ether sedimentation and saturated salt floatation) significantly improved the sensitivity from 3 to $9 \%$ for detection of ova/cysts of parasites as compared to routine iodine preparation technique. The modified formol-ether sedimentation procedure showed a highest sensitivity for the parasitic detection. The supplementation of the routine method with floatation and the sedimentation technique will improve the diagnostic accuracy when this is compared to the routine method alone.

\section{Introduction}

In developing countries intestinal parasitic infection is one of the serious health problems and approximately $10 \%$ of the population is infected with intestinal worms (1). Intestinal parasitic diseases are still a significant cause of morbidity in these countries and hence warrant prompt diagnosis and treatment (2). Commonly used methods for the detection of 
intestinal parasite for stool examination are direct and concentration techniques (3). Due to low density of parasites in the faeces, direct wet mount method can miss parasites (ova, cysts) and the detection can be enhance through using concentration techniques. Concentration techniques are considered to be better as they are supposed to increase the yield and the positivity rate. The main purpose of this technique is to isolate parasites and ova from fecal debris $(4,5)$. The present study was conducted with an aim to determine the prevalence of intestinal parasitic infection in a tertiary care hospital and to compare the stool concentration techniques with direct routine microscopic examination for detection and identification of intestinal parasites.

\section{Materials and Methods}

This prospective study was conducted in a Tertiary care hospital at Lucknow in the department of Microbiology after obtaining the institutional research and ethical committee clearance. During the study period of six month total of 118 stool samples were received for diagnosis of parasitic infections (January 2018 to June 2018).

\section{Inclusion Criteria}

Patients attending outdoor units and admitted in wards with symptoms suggestive of intestinal parasitic infection such as diarrhea, vomiting, nausea, abdominal pain, and weight loss.

\section{Exclusion}

Patients who had received antihelminthic drugs within 3 months of beginning of study were excluded.

Accompanying guardian/patient not willing to give consent for their patient participation in the study

\section{Laboratory Examination $(6,7)$}

\section{Macroscopic examination}

All the stool samples were observed for colour, consistency, presence of mucus, blood, adult intestinal helminths and segment of tapeworm.

\section{Direct Microscopic Examination}

On a $1 \mathrm{~mm}$ thick microscopic slide, a small amount of stool sample was emulsified in 1-2 drops of saline or iodine solution. A cover slip was placed on it by taking care that the preparation was free of air bubbles and macroscopic debris, followed by microscopic examination for parasitic ova \& cysts.

\section{Microscopic examination after the various stool concentration techniques}

All these stool samples were processed by formal ether concentration method and zinc sulphate floatation method and compared with the findings of direct wet mount $(6,7,8)$.

Stool samples were handled with proper personal protection aids. The results were compared and analyzed.

\section{Simple salt floatation}

Briefly, about $1 \mathrm{gm}$ of faeces was emulsified with 3-4 ml of saturated salt solution in a $20 \mathrm{ml}$ glass test tube. It was stirred well and more salt solution was added till the container was nearly full, with the stirring being continued.

Any coarse matter which floated up was removed and the tube was placed on a leveled surface with a glass slide being placed over the top of the tube, which was in contact with the fluid. It was allowed to stand for 30 minutes. The slide was removed and observed for the presence of ova/cysts. 


\section{Zinc sulphate centrifugal floatation}

$1 \mathrm{~g}$ of the stool specimen was emulsified in 10 parts of tap water and it was strained through a wire gauze. The filtrate was collected in a centrifuge tube and centrifuged at 2,500 rmp. The supernatant was discarded and the sediment was re-suspended in water. This step was repeated till the supernatant became clear. To the sediment, 3-4 $\mathrm{ml}$ of 33\% Zinc sulphate solution was added, it was mixed well and it was filled with $\mathrm{ZnSO}_{4}$ solution, about half an inch of the rim. Several loopfuls of the supernatant fluid were removed with a bacteriological loop and they were observed for parasites.

\section{Formol-ether concentration}

$1 \mathrm{~g}$ of stool was emulsified in $7 \mathrm{ml}$ of $10 \%$ formol saline and it was kept for 10 minutes for fixation. It was then strained through a wire gauze. The filtrate was added to $3 \mathrm{ml}$ of ether and it was centrifuged at $2000 \mathrm{rpm}$ for 2 minutes. It was allowed to settle. The supernatant was removed and a wet mount was made of the deposit to look for parasites.

\section{Statistical analysis}

Chi-square test was used to evaluate the statistical significance, $\mathrm{P}$-value $<0.05$ was considered as statistically significant.

\section{Results and Discussion}

A total of 118 stool samples were examined in our study, out of which 46 (38.9\%) samples were positive for intestinal parasitic infestation, as were observed by the different parasitic diagnostic methods (direct and concentration). In our study we found that formal ether sedimentation technique (44.1\%) as a most sensitive method for detection of intestinal parasitic infection followed by zinc sulphate centrifugal floatation technique (42.4\%) and direct microscopy (30.5).Table 1

The sensitivity of zinc sulphate floatation method and formal ether sedimentation technique were more than the direct microscopic methods, we found 14 more parasites by zinc sulphate floatation method and the total of 52 parasites were detected by formal ether sedimentation technique with excess of 16 parasites from direct method.

As a patient can harbour more than one parasite so the number of parasites were outnumbered the cases. We found 6 patients have double parasitic infestation by zinc sulphate centrifugal floatation method and 6 by formal ether sedimentation technique. The most common dual infection was the infestation of Entamoeba histolytica/dispar cyst with Blastocystis hominis cyst.

Among the isolated parasites the most common intestinal infection was the infestation of Entamoeba histolytica/dispar 24 (20.33\%) followed by Blastocystis hominis 14 (11.86\%), Entamoeba coli 8 (6.77\%), Giardia lamblia $6(5.08 \%)$ by the Formal-ether sedimentation technique which was the most sensitive method.(Table:2)

In developing countries parasitic infestations are an important cause of morbidity and mortality. The diagnosis of parasitic infestations in humans requires skills to identify and differentiate them from one another. Routine diagnostic procedures have low sensitivity. There is significant increase in parasitic detection after concentration in our study.

Protozoan cysts were observed by direct microscopy method and two concentration methods (zinc sulphate floatation and formalether sedimentation method). 
Table.1 Sensitivity of different parasitic diagnostic methods

\begin{tabular}{|c|c|c|}
\hline Procedure & $\begin{array}{c}\text { Number of positive } \\
\text { samples }\end{array}$ & Number of total parasites \\
\hline $\begin{array}{c}\text { Direct microscopy } \\
\text { (saline and iodine mount) }\end{array}$ & $36(30.5)$ & $36(30.5)$ \\
\hline $\begin{array}{c}\text { Zinc Sulphate centrifugal } \\
\text { floatation technique }\end{array}$ & $40(33.9)$ & $50(42.4)$ \\
\hline $\begin{array}{c}\text { Formal-ether sedimentation } \\
\text { technique }\end{array}$ & $46(38.9)$ & $52(44.1)$ \\
\hline
\end{tabular}

Figures in parenthesis indicate percentage

Table.2 Prevalence of Parasitic Infection by different parasite detection technique

\begin{tabular}{|c|c|c|c|}
\hline Name of Parasites & $\begin{array}{c}\text { No. of parasites by } \\
\text { direct microscopy }\end{array}$ & $\begin{array}{c}\text { No. of parasites } \\
\text { by ZnSO4 } \\
\text { method }\end{array}$ & $\begin{array}{c}\text { No. of parasites by } \\
\text { formal-ether }\end{array}$ \\
\hline $\begin{array}{c}\text { Entamoeba } \\
\text { histolytica/dispar }\end{array}$ & 19 & 23 & 24 \\
\hline Blastocystis hominis & 7 & 13 & 14 \\
\hline Entamoeba coli & 6 & 8 & 8 \\
\hline Giardia lamblia & 4 & 6 & 6 \\
\hline Total & 36 & 50 & 52 \\
\hline
\end{tabular}

Fig.1 Cyst of Blastocystis hominis, Giardia lamblia, Entamoeba histolytica/dispar, E. histolytica/dispar and Entamoeba coli (left to right)

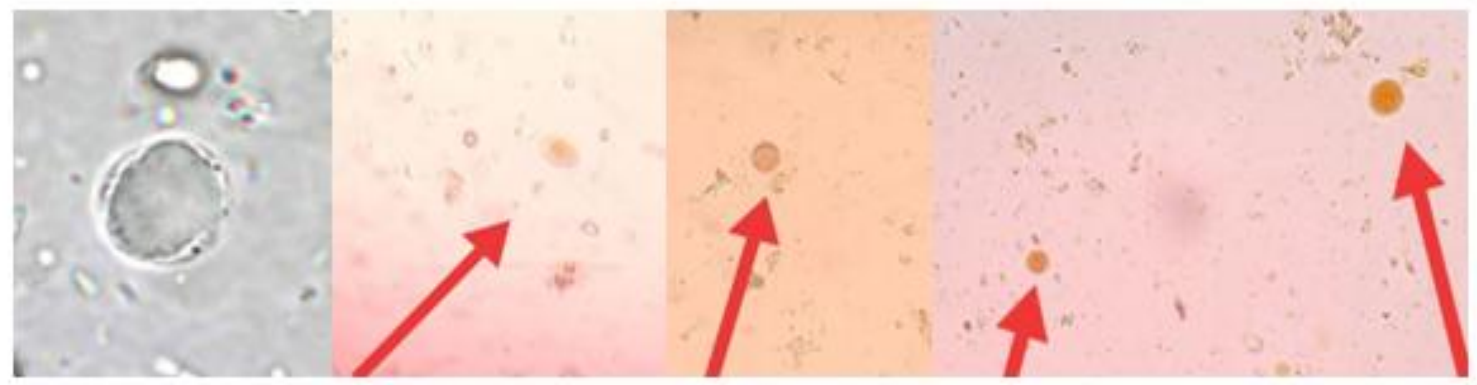

Among 118 samples the positivity by direct method is $30.5 \%$, by zinc sulphate floatation technique is $42.4 \%$ and by formal-ether sedimentation technique is $44 \%$.

The present study findings were in agreement with the findings of Khyati Jain et al.,(9) and Parameshwarappa KD et al.,(10). In their studies $23 \%$ parasites were found by direct wet mount while it increased to $36 \%$ after concentration of stool sample and $38 \%$ parasites were found by direct wet mount which increased to $64.8 \%$ after concentration of stool sample respectively.

In contrast to the present study, Amin et al., (11) found Zinc Suplhate flotation method $(49.3 \%)$ as the most sensitive method than 
formal ether sedimentation technique (43.3\%). Results of our study is also in contrast with the study that found $60 \%$ by Mahmood et al.,(12) in Baghdad by the flotation, $58.7 \%$ by sedimentation and $39.3 \%$ by direct wet mount.

In our study, additional 14 intestinal parasites were detected by zinc sulphate centrifugal floatation technique while 16 intestinal parasites were detected by formal ether sedimentation technique as compared to direct microscopic methods.

In the present study the intestinal protozoan parasite Entamoeba histolytica/dispar (20.3\%) was the most prevalent species followed by Blastocystis hominis (11.8\%). This was in agreement with the study done by Sahai $\mathrm{S}$ and Jamali S(13), in which total of 755 cases were analyzed 133 cases were found to be affected with parasitic infestations, with a prevalence of $17.6 \%$. Among them Entamoeba histolytica/dispar was found to be the most common parasite $(9.3 \%)$ followed by Blastocystis hominis (3.3\%), Giardia lamblia (3\%). This was also in agreement with the study done by Amin and Parameshwarappa $(10,11)$.

In our study, we compared formol ether sedimentation and zinc sulphate centrifugal floatation technique for detection of intestinal parasites. Stool concentration methods are usually performed when direct smear fails to reveal any parasites. The concentration of stool allows detection of even a small number of parasites in the stool specimen. These procedures allow the increased recovery of eggs and protozoal cysts. The trophozoites are destroyed during concentration procedure.

Zinc sulphate floatation and saturated salt floatation are most frequently used methods of concentration. Many helminthic eggs and protozoal cysts can be recovered and demonstrated by floatation methods but the high specific gravity of the fluid may cause distortion in the morphology of eggs and cysts of enteroparasites. The basic disadvantage of the floatation technique is that unfertilized eggs of Ascaris lumbricoides, eggs of Taenia saginata and Taenia solium, all trematode eggs and larvae of Strongyloides stercoralis do not float because these are heavier than the suspending liquid. Sedimentation techniques are easy to perform and technical error is also less. They are more sensitive than floatation methods and morphology of helminthic eggs and protozoal cysts is preserved $(6,7)$.

Early and prompt diagnosis of intestinal parasitic infestations is important as this contributes to malnutrition, growth retardation and diminished work capacity, in addition to morbidity and mortality.

The formal-ether sedimentation technique showed a high sensitivity for the parasite detection. Commonly detected parasites in this study are cysts of Entamoeba histolytica/dispar (20.3\%), cysts of Blastocystis hominis (11.8\%), cysts of Entamoeba coli (6.7\%), and cysts of Giardia lamblia $(5.1 \%)$ by the concentration methods.

The prevalence of parasitic infections remains high because of malnutrition, unhygienic condition, bad sanitation, the improper disposal of sewage and the non-availability of potable water supplies. The formol-ether technique and the zinc sulphate flotation technique can be used in combination to increase the diagnostic sensitivity.

\section{References}

1. Sayyari A, Imanzadeh F, Bagheriyazdi S, Karami H, Yaghoobi M. Prevalence of intestinal parasitic infections in the Islamic republic of Iran. Eastern Mediterranean Health Journal 2005; 11:377-383. 
2. Procop G W. Gastrointestinal infections. Infect Dis. Clin. North Am 2001;15:1073-108.

3. Arora D R, Arora B. Medical Parasitology. 2nd ed. New Delhi: CBS publishers. 2005:665-779.

4. Cheesbrough, M. District Laboratory Practice in Tropical Countries, 3rd Edition, Part One, Cambridge University Press, Cambridge 2000; 214-215.

5. B. M. Shanker Venkatesh, S, Rajeshwar Rao, N. Vivekanand, B. M. Shanker Venkatesh. A Comparative Study of Concentration Techniques for Detection of Intestinal Parasitic Infections-to Evaluate the Prevalence And to Identify A Better Method of Concentration Technique At A Tribal tertiary Care Hospital. IOSR Journal of dental and Medical Sciences(IOSRJDMS) July 2016.

6. Garcia L. S. 2007. Diagnostic Medical Parasitology. Intestinal cestodes. 5th ed. Washington, DC: ASM Press, Chapter 13; p. 376-7.

7. Arora D R, Arora B. Medical Parasitology. 2nd ed. New Delhi:CBS publishers. 2005:665-779.

8. Ramakrishnan K, Kali A, Charles M V P and Kunigal S S. Comparative Evaluation of Three Stool Concentration Techniques in the Diagnosis of Intestinal Parasitic Infections. Pondicherry,
India.2016:511,032.

9. Jain K, Arjun S. Gurjar and Madhurendra S. Rajput. A cross sectional study for prevalence of intestinal parasitic infestation by using saline, iodine, glycerol-iodine, $\mathrm{KOH}$ and LPCB wet Mount preparations of stool samples from patients attending AIIMS, Dewas MP(2018)7(5):3449-3457.

10. Parameshwarappa K D, Chandrakanth $C$, Sunil B. "The Prevalence of intestinal parasitic infestations and the evaluation of different concentration techniques of the stool examination. Journal of Clinical and Diagnostic Research, 2012 September (Suppl), Vol-6(7): 1188-1191.

11. Amin $\mathrm{H}$ A \& Ali S A K. Evaluation of different techniques of stool examination for intestinal parasitic infections in Sulaimani City-Iraq. International Journal of Current Microbiology \& Applied Sciences 2015;Vol. 4 (5): 991-996.

12. AL-Kubaisy, W., AL-Talib, H., Alkhateeb, A., and Shanshal, M M. 2014. Intestinal Parasitic Diarrhea among Children in Baghdad- Iraq. Tropical Biomedicine.31(3): 499-506.

13. S Sahai and S Jamali. Changing trend in prevalence of intestinal parasites in patients attending a tertiary care hospital in Lucknow. IJBAMR. 2015;4(2):560-7.

\section{How to cite this article:}

Sana Jamali, Sarver Jahan and Megha Chaudhary. 2021. Comparison of Routine and Stool Concentration Techniques for Microscopic Detection of Intestinal Ova and Cysts in the Tertiary Care Hospital of Northern India. Int.J.Curr.Microbiol.App.Sci. 10(12): 22-27. doi: https://doi.org/10.20546/ijcmas.2021.1012.004 